\title{
El recurso de nulidad en el Código Procesal Penal, DESDE LA PERSPECTIVA DE LA CONSTITUCIÓN
}

\section{Miguel Ángel Fernández GonZÁlez*}

RESUMEN: El autor examina el recurso de nulidad contemplado en el Código Procesal Penal, ocupándose de analizar, especialmente, la causal contemplada en el artículo 373 letra a) de dicho Código, al tenor del cual procede la declaración de nulidad del juicio oral y de la sentencia definitiva o solo de esta. En especial se analiza la fuerza normativa de la Constitución Política y el proceso de constitucionalización del Derecho y, por ello, expresión positiva del proceso de constitucionalización del Derecho.

Palabras clave: Recurso de nulidad - Constitución Política Constitucionalización del Derecho.

\section{The Annulment action in the Criminal Procedural CODE, FROM THE CONSTITUTION'S PERSPECTIVE}

ABSTRACT: The author studies the annulment acction included in the Criminal Procedural Code, especially analyzing the consideration contained in article 373 letter a) of said Code. According to it there proceeds the annulment decree of the oral trial and the final sentence or only of the latter. The binding authority of the Constitution and of the process of constitutionalization of the Law, are examined.

KEY wORDS: Annulment action - Constitution - Constitutionalization of the Law.

SUMARIO: I. Introducción. II. Fuerza normativa y constitucionalización del Derecho. 1. Aplicación directa de la Constitución. 2. Consecuencias. 3. Reconocimiento en el Código Procesal Penal. 4. Rol de los jueces. III. Régimen de

Abogado. Magíster en Derecho Público, Pontificia Universidad Católica de Chile; Magíster en Investigación Jurídica, Universidad de los Andes. Profesor de Derecho Político y Constitucional en las Universidades Católica, de Chile y de los Andes (CHILE). Es Secretario de la Asociación Chilena de Derecho Constitucional y miembro del Consejo Nacional Editorial del Centro de Estudios Constitucionales. Email: mafernande@cb.cl

Fecha de recepción: 31 de enero de 2008.

Fecha de aprobación: 26 de mayo de 2008. 
recursos en el Código Procesal Penal. 1. Examen constitucional. 2. Jurisprudencia nacional. 3. jurisprudencia internacional. IV. Nulidad por infracción de la Constitución o de los Tratados. 1. Antecedentes. 2. Oportunidad de la infracción. 2.1. Argumentos en contra. 2.2. Argumentos a favor. 3. Legitimación activa. 4. Naturaleza de la infracción. 5. Objeto de la infracción. V. Conclusiones.

\section{INTRODUCCIÓN}

Agradezco la invitación que nos formulara la Universidad Católica del Norte para participar en este seminario, dedicado a revisar Instituciones prácticas de Derecho Constitucional, que ha organizado conjuntamente con la Asociación Chilena de Derecho Constitucional, en el cumplimiento de la tarea que se ha propuesto nuestra Asociación, en orden a celebrar encuentros académicos en las regiones del país, en conjunto con las respectivas Facultades de Derecho.

En esta oportunidad se me ha pedido examinar el recurso de nulidad, contemplado en el Código Procesal Penal, ocupándome de analizar, especialmente, la causal contemplada en el artículo 373 letra a) de dicho Código, al tenor del cual procede la declaración de nulidad del juicio oral y de la sentencia definitiva o solo de esta "cuando, en cualquier etapa del procedimiento o en el pronunciamiento de la sentencia, se hubieren infringido sustancialmente derechos o garantías asegurados por la Constitución o por los tratados internacionales ratificados por Chile que se encuentren vigentes".

Sin embargo, comienzo explicando cómo esa causal de nulidad es concreción, en nuestro Derecho Positivo, de la fuerza normativa que es de la esencia de la Carta Fundamental que nos rige y, por ello, expresión positiva del proceso de constitucionalización del Derecho.

\section{Fuerza normativa y Constitucionalización del Derecho}

Una de las más gravitantes transformaciones ${ }^{1}$ del Constitucionalismo Humanista $^{2}$ se encuentra en que, ahora, las Cartas Fundamentales poseen vigor jurídico propio, lo cual obliga a incorporar y aplicar sus principios

CEA Egaña, José Luis (2003) "Aproximación a la teoría constitucional contemporánea". Estudios Constitucionales, Año $1 \mathrm{~N}^{\circ} 1$, p. 37.

2 Fernández González, Miguel Ángel (2005) "Bases de los Tribunales Constitucionales en el constitucionalismo humanista". Humberto Nogueira Alcalá (coordinador) Jurisdicción constitucional en Chile y América Latina: presente y prospectiva, Santiago: LexisNexis, pp. 7-38; y É1 mismo (2005) "Constitución y casación: ¿ de la falta de aplicación al monopolio constitucional?". Estudios Constitucionales, Año 3 Nº 1, pp. 97-126. 
y normas en cada evento donde estén en juego derechos fundamentales, a diferencia del Constitucionalismo del Estado, caracterizado por Declaraciones de Derechos que constituían expectativas a ser actualizadas por el legislador, o sea y en último término, por las fuerzas políticas dominantes en cada momento. A partir de ello y por lo mismo, el Derecho completo se constitucionaliza.

\section{Aplicación directa de la Constitución}

En esta línea de pensamiento, el artículo $6^{\circ}$ inciso $2^{\circ}$ de nuestra Constitución acoge aquel principio ${ }^{3}$ y lo positiviza, disponiendo que los preceptos contenidos en ella obligan tanto a los titulares o integrantes de los órganos estatales como a toda persona, institución o grupo, con lo cual queda consagrada, en el Derecho Positivo chileno, la fuerza normativa aludida, tendiente a lograr que efectivamente impere el principio de supremacía constitucional, consagrado en el inciso $1^{\circ}$ del mismo artículo.

Ello significa que los preceptos contenidos en la Constitución son obligatorios y no constituyen programas, proyectos, idearios o planes, poseyendo energía normativa propia, lo cual posee consecuencias gravitantes para todas las decisiones, estatales o privadas, que se adopten en el Estado Constitucional y Democrático de Derecho.

En efecto, surge para todos los órganos del Estado y, en realidad para todas las personas, la obligación de interpretar y aplicar los preceptos y cláusulas jurídicas conforme a los principios y normas contenidos en la Carta Fundamental, o sea, visualizando el Sistema Jurídico desde y hacia la Constitución.

Aquella forma de concebir el Ordenamiento Jurídico exige respetarla en el desenvolvimiento concreto de las conductas públicas y particulares, de manera que ellas no solo se atengan a ella en la secuencia dispuesta para su generación y cuando se las confronta, sustantivamente, sea en concreto o en abstracto, con la preceptiva fundamental, sino que también cuando esas actuaciones son llevadas a la práctica, aunque no se hayan planteado dudas de constitucionalidad, en sede preventiva o a posteriori, o no obstante que hayan sido desechadas, en el control respectivo ${ }^{4}$.

Bulnes Aldunate, Luz (1998) "La fuerza normativa de la Constitución". Revista Chilena de Derecho, Número Especial, p. 137 . Véase el considerando $10^{\circ}$ de la sentencia pronunciada por el Tribunal Constitucional el 27 de octubre de 1983, Rol No 19; CEA EgAÑa, José Luis (1999) El sistema constitucional de Chile. Síntesis crítica. Valdivia: Facultad de Ciencias Jurídicas y Sociales de la Universidad Austral de Chile, p. 180; y Él mismo (2002) Derecho Constitucional Chileno. Tomo I. Santiago: Ediciones Universidad Católica de Chile, pp. 237-238 y 244-246.

4 Fernández GonzÁlez, Miguel Ángel (2001) "La fuerza normativa de la Constitución”. Revista de Derecho Público Vol. LXIII, Tomo I, pp. 77-102. 


\section{Consecuencias}

Primera secuela inevitable de la fuerza normativa es que los preceptos constitucionales no requieren mediación normativa alguna para aplicarse a los hechos o situaciones concretas regidas por ellos, a menos que el propio Poder Constituyente haya impuesto, con el rasgo de deber, la necesidad de dicha mediación y quedando, en este caso, el legislador expuesto a incurrir en inconstitucionalidad por omisión.

Así, en el primer caso, esto es, cuando el precepto constitucional no requiere de mediación por parte de otra especie de disposición jurídica, la fuerza normativa se expresa en la obligatoriedad para todos -órganos estatales, personas, instituciones o grupos- en orden a respetar la preceptiva constitucional, aplicándola directamente y sin dilación, aun cuando no exista disposición complementaria alguna, ni siquiera aquella que regula la forma o procedimiento conforme al cual deba dársele vigencia concreta a la norma constitucional, pues, en este caso, el órgano convocado a darle tal aplicación deberá, incluso, configurar aquel procedimiento acudiendo a las normas del Derecho Común o, en último término, a los principios y reglas generales del Derecho.

En el segundo caso, vale decir, tratándose de preceptos en que el Poder Constituyente ha impuesto, expresamente, la necesidad de mediación normativa, entonces, la fuerza normativa del Código Político se concreta, como anticipaba, en requerir del órgano competente-que usualmente serán los Tribunales-, la constatación del incumplimiento del deber por parte de quien tenía que complementar el precepto constitucional, sin que pueda ese Tribunal obligar o conminar al ente estatal remiso a normar, pero habilitando para que operen los mecanismos de control de la responsabilidad política o institucional y, eventualmente, las indemnizaciones de perjuicios que sean procedentes. Empero, si de aquella omisión se sigue la infracción de derechos fundamentales, entonces, junto con declararla, el Tribunal debe proceder a la aplicación directa e inmediata de la preceptiva constitucional en la defensa de los derechos esenciales.

En concreto, la fuerza normativa no implica, necesariamente, que los preceptos constitucionales no requieran mediación de otras disposiciones jurídicas, usualmente de la ley, sino que dicha energía consiste en que se puede requerir, ante el Tribunal competente, la aplicación, directa e inmediata, de toda disposición constitucional ${ }^{5}$, aunque la secuela que se derive

En este sentido, útil es advertir que este no es un modelo siempre seguido en el Derecho Comparado, pues existen Sistemas Constitucionales en los cuales el Principio de Vinculación Directa se aplica solo a la Parte Dogmática, v. gr., el artículo $18^{\circ}$ de la Constitución de Portugal, el artículo $1^{\circ}$ párrafo $3^{\circ}$ de la Constitución de la República Federal de Alemania. 
de esa omisión sea diversa, pues y en primer lugar, si de ella se sigue la lesión de derechos constitucionales, el Tribunal deberá impetrar las medidas para su protección; y, de otra, si no se produce aquella vulneración, entonces, la sentencia se limitará a constatar la omisión, dejando su secuela sancionatoria a los órganos de control de la responsabilidad política o institucional ${ }^{6}$.

Una segunda consecuencia de la fuerza normativa de la Constitución radica en que, a partir de ella, todos los Tribunales deben preterir cualquier norma infraconstitucional, incluyendo obviamente las de carácter legal, que sea contraria a la Carta Fundamental, atendido que no hay duda alguna que el artículo $6^{\circ}$ inciso $2^{\circ}$ de ella se aplica también a los Órganos Jurisdiccionales, sean estos los que integran el Poder Judicial, aquellos que no quedan, conforme al artículo 82 inciso $1^{\circ}$ del Código Político, sujetos a la superintendencia de la Corte Suprema, o aun los de carácter especial, como son los que emanan de la denominada Jurisdicción Doméstica ${ }^{7}$ o los de naturaleza arbitral.

Lo anterior porque si los jueces dan valor a una norma contraria a la Constitución es indubitado que están obrando fuera de su competencia, pues el arco de atribuciones que les confiere la Carta Fundamental y las leyes no les permite aplicar disposiciones contrarias a aquella, sino que -antes y al contrario- les ha ordenado dar aplicación a la Constitución, preteriendo las disposiciones legales o infralegales que la vulneran. De esta forma cumplen, entonces, lo dispuesto en el artículo $7^{\circ}$ incisos $1^{\circ}$ y $2^{\circ}$ de la Constitución.

Por ende, cualquier Tribunal puede $-y$, repito, debe- dejar de considerar, para su pronunciamiento el precepto legal que, incidiendo en él, sea, sin embargo, contrario a la Constitución. De otra forma, la vinculación directa preconizada por el Poder Constituyente operaría en todos los casos y respecto de todos los entes, públicos y privados, con excepción de los jueces ${ }^{8}$.

La tercera consecuencia que cabe asignar a la fuerza normativa, de la cual surge el proceso jurídico, político y cultural que ha viene denominándose constitucionalización del Derecho, estriba en que todas las normas jurídicas, entre las que se encuentran los preceptos legales, los actos de la Administración y de los demás órganos públicos y las cláusulas contractuales $^{9}$, cualesquiera sean sus destinatarios o la situación de hecho que re-

FERNÁNDEZ GONZÁLEZ (2001) 79.

En aplicación concreta, léase FERnÁNdez GonzáLEZ, Miguel Ángel (1999) "Recurso de protección y jurisdicción doméstica", Revista Chilena de Derecho, vol. XXVI N 3 , pp. 761-781.

8 FERNÁNDEZ GONZÁLEZ (2001) 97-98.

9 FernáNDEZ GonZÁLeZ, Miguel Ángel (2002) "Fundamentos constitucionales del derecho de los contratos: Intangibilidad, autonomía de la voluntad y buena fe". En Hernán Corral Talciani (editor). Cuadernos de Extensión Jurídica $\mathrm{N}^{\circ}$ 6, Universidad de los Andes, pp. 17-46. 
gulen, tienen que ser interpretados y aplicados conforme a los principios, valores y preceptos contenidos en la Carta Fundamental.

De esta manera, la fuerza normativa no solo implica el efecto más radical, consistente en excluir del ordenamiento jurídico las normas contrarias a la Carta Fundamental, en virtud del principio de supremacía constitucional, sino que también exige que aquellas normas, para que sean efectivamente coherentes con la preceptiva contenida en el Código Político, se interpreten y lleven a la práctica en armonía con aquel estatuto jurídico fundamental.

En este contexto, no puede ser discutido que la penetración de los principios y normas contenidos en la Constitución hacia todas las áreas del Derecho, constituye una tendencia insoslayable hace ya tiempo, sobre todo con miras al respeto y promoción de los derechos fundamentales. Por ende, reducir las normas contenidas en la Carta Fundamental a la regulación del Estatuto del Poder, entendiendo por tal los órganos del Estado, no solo constituye una visión ya superada dentro del sistema político y constitucional contemporáneo, sino que resulta contraria, sin más, a la posición que ha ido adquiriendo el Derecho de la Constitución en Sistemas Jurídicos respetuosos de los principios y valores cardinales sobre los cuales se sitúa y construye la sociedad ${ }^{10}$.

\section{Reconocimiento en el Código Procesal Penal}

Resulta indudable que la aplicación directa de la Constitución alcanza, a no dudarlo, al Código Procesal Penal, desplegándose a su respecto la fuerza vinculante que, en texto expreso, consagra la Base de la Institucionalidad prevista en el artículo $6^{\circ}$ inciso $2^{\circ}$ de la Carta Fundamental. Asimismo, la fuerza normativa obliga a todos y, entre ellos, especialmente a los tribunales, a interpretar y aplicar las normas de dicho Código de forma tal que aquella hermenéutica y secuela práctica hagan de él, en su texto, contexto, espíritu y ejecución, una normativa coherente y respetuosa de la Constitución.

Más concretamente, vale la pena anticipar que estas ideas adquieren particular relevancia cuando se trata de indagar en torno de la aplicación de los principios fundamentales normativizados en el Nuevo Código y en su legislación complementaria a hechos y lugares, en principio, no alcanzados por la Reforma Procesal Penal; y al captarse que es el mismo Código Procesal Penal, en su artículo $373^{\circ}$ letra a) ${ }^{11}$, el que ordena la aplicación

10 Domínguez Águila, Ramón (1999) "Prólogo". En Castellón Venegas, Hugo A. y ReBolledo Contreras, Laura E. Aspectos sobre la constitucionalización del Derecho Civil. Santiago: Ed. ConoSur, pp. 1-2. 
directa de la Constitución y de los tratados internacionales vigentes en Chile, dotando no solo a aquella, sino también a estos, de vigor jurídico inmediato:

"Es decir, si en una etapa prerreforma podíamos concluir que los jueces autolimitaban sus facultades para pronunciarse constitucionalmente sobre las sentencias judiciales, con el recurso de nulidad introducido por la reforma, en cambio, tenemos a la vista un nuevo escenario en que los ministros de Corte Suprema, ahora pueden y deben vigilar que las sentencias judiciales respeten los derechos fundamentales"12.

Con todo, debe comprenderse bien que la constitucionalización, sobre la base de la fuerza normativa vinculante del Código Político, no supone el desaparecimiento de las categorías y reglas que regulan la interpretación y aplicación de la ley o, en este caso, del Código Procesal Penal, y menos su reemplazo por las que contempla la Carta Fundamental y que se aplican solo a ella. Se trata, antes y al contrario, de razonar a partir de la Constitución y dentro de los parámetros que ella fija, aun en aquellas materias reguladas por el Nuevo Código de Enjuiciamiento Criminal:

"No se trata, como pudiera creerse, de una publificación de las relaciones jurídicas, sino que estas pasan a recibir de los principios y preceptos constitucionales un nuevo y actual sentido vitalizador que informan la aplicación e interpretación de las normas civiles"13.

Por ello, no procede excluir o siquiera mitigar el alcance y extensión de las categorías y reglas que imperan en la interpretación y aplicación de la ley, de los actos administrativos, de las sentencias y resoluciones judiciales o de las cláusulas contractuales, cada uno de los cuales tiene, además, normas y principios hermenéuticos propios, sino que aquella interpretación y aplicación debe ahora y siempre hacerse desde y hacia la Constitución, lo cual implica, por una parte, cuidar con celo la distribución de potestades y competencias entre los órganos estatales dispuesta por el Código Político y, superlativamente, como viene siendo dicho con majadería ineludible, el respeto y promoción de los derechos fundamentales.

En otras palabras y hablando directamente, el plexo de valores que se encuentra normativizado en la Constitución, comenzando por la efectiva vigencia de los derechos fundamentales, primero ante el Estado, pero también en las relaciones entre particulares ${ }^{14}$, invade, inunda y

12 Lovera Parmo, Domingo (2005), "Notas sobre el control de constitucionalidad de las sentencias y el recurso de nulidad". Gaceta Jurídica N N $^{\circ} 05$, p. 34.

13 Rioseco Enríquez, Emilio (1996) El Derecho Civil y la Constitución ante la jurisprudencia. Santiago: Editorial Jurídica de Chile, p. 9.

14 Fernández González, Miguel Ángel (2003) "Renunciabilidad de los derechos fundamentales de contenido económico". En Actas del VIII Congreso Iberoamericano de Derecho Constitucional, Sevilla: 3 al 5 de diciembre [versión en CD]; y Él mismo (2004) "Constitucionalización del Derecho Civil. Eficacia horizontal y renunciabilidad de los derechos fundamentales". Temas de Derecho, Universidad Gabriela Mistral, Año XIX N 1 y 2, pp. 207-243. 
se despliega a lo largo y ancho de todo el Sistema Jurídico, incluyendo ciertamente el Código Procesal Penal y los procesos desarrollados conforme a él.

Con todo, el sometimiento de la ley a la Constitución, en el Constitucionalismo Humanista, no deviene del reconocimiento y aplicación de un simple y elemental principio jerárquico que distribuye competencias normativas entre las fuentes del Derecho, sino que arranca de la obligatoriedad que pesa también sobre la ley de respetar el orden de valores que se ha constitucionalizado, manifestación de lo cual es la creciente atribución conferida o acertadamente asumida por los Tribunales en orden a velar, directamente, por el respeto de esos valores, v. gr., en el ya referido artículo $373^{\circ}$ letra a) del Código Procesal Penal; o, en un ámbito del todo diverso, en el nuevo artículo $485^{\circ}$ del Código del Trabajo, a partir del $1^{\circ}$ de marzo de 2007, conforme a la Ley $\mathrm{N}^{\circ} 20.087$, publicada en el Diario Oficial el 3 de enero de 2006.

\section{Rol de los jueces}

Es indudable, para concluir estas reflexiones iniciales, que, correlativa y proporcionalmente a la periclitación de la ley, surge la elevación de la Judicatura que, en el constitucionalismo del Estado, quedaba constreñida a ser la boca que pronunciaba las palabras de la ley ${ }^{15}$.

Jueces independientes ${ }^{16}$, entonces, deben ser los garantes de la Constitución, especialmente del respeto por los órganos del Estado y por los particulares de los derechos fundamentales, sobre todo cuando estos se encuentran garantizados en la Carta Fundamental y en los tratados internacionales, como lo exige el artículo $5^{\circ}$ inciso $2^{\circ}$ de aquella:

“¡la relación del hombre con la ley ha cambiado totalmente! (...).

Para esto (la noción de Montesquieu respecto de la función judicial) había que partir de un supuesto doble: por un lado, la ley era (...) la ratio convertida en norma (...) En segundo lugar, se consideraba que las mejores garantías para que la justicia de las leyes quedara protegida radicaban en la entrega de la función legislativa al Parlamento, a los elegidos (...).

Ambos supuestos han desaparecido hoy en gran parte (...)"17.

$\mathrm{Y}$ a este respecto, no se olvide que ${ }^{18}$ :

"El Parlamento llegó al apogeo de su poder, eficiencia y prestigio en el cambio de siglo, para exhibir después, con raras excepciones, su declive aparejado del vigorizamiento del Ejecutivo con sus anexos tecnoburocráti$\cos (\ldots)$. 
Las causas de esa periclitación fueron múltiples, aunque semejantes en los países que la padecieron.

(...) no era -como se pretendía- el foco de discusión transparente y argumentada ni de libre elaboración de decisiones racionales, pues sus miembros carecían de la preparación indispensable, eran meros delegados obedientes a las órdenes de los partidos o se mezclaban en conflictos de intereses con secuela de corrupción (...) la inoperancia de las Asambleas enmarañadas en debates interminables y en querellas entre tiendas políticas polarizadas, por lo cual tampoco conseguían respuestas adecuadas a las reformas que demandaba la mayoría indigente. El Parlamento, en síntesis, no era representativo en la democracia formal que se vivía, porque tampoco cumplía los roles que se le asignaban en el ordenamiento constitucional (...).

Causa muy relevante de la declinación del Parlamento fue la crisis del concepto clásico de ley (...)"19.

Surge nítida, por ende, una consecuencia del Constitucionalismo Humanista, consistente en que el juez es el supremo garante de la Constitución y, su sentencia, la última palabra en la defensa de los derechos fundamentales ${ }^{20}$, sin que pueda confundirse esto, claro está, con poder omnímodo e ilimitado:

"Los americanos han conferido, pues, a sus tribunales un inmenso poder político, pero al obligarles a no atacar las leyes sino por medios judiciales han reducido grandemente los peligros de ese poder"21.

En resumen, la evolución del régimen democrático constitucional, sobre todo en nexo con las funciones legislativa y judicial, ha derivado en que sean los Tribunales quienes asuman el rol de garantes de la Constitución, en expresión inequívoca e indiscutida del principio de supremacía, única forma de garantizar el respeto por todos de los derechos humanos, con fuerza normativa directa.

\section{Régimen de recursos en el Código Procesal Penal}

Antes de avanzar en la causal de nulidad contenida en el artículo 373 letra a) del Código Procesal Penal, recuerdo, sinópticamente ${ }^{22}$ y en lo que

19 Cea Egaña, José Luis (1990) "El Parlamento en el futuro del Derecho y de la democracia". Revista Chilena de Derecho, vol XVII N ${ }^{\circ}$ 1, p. 28.

20 Considerando $11^{\circ}$ de la sentencia pronunciada el 20 de septiembre de 1989 , Rol $N^{\circ} 78$. Asimismo, véase el considerando $6^{\circ}$ de la sentencia pronunciada el 27 de diciembre de 1990, Rol $N^{\circ} 116$; el considerando $22^{\circ}$ de la sentencia pronunciada el 18 de junio de $1991, R_{o l} N^{\circ}$ 124; y el considerando $21^{\circ}$ de la sentencia pronunciada el 21 de abril de $1992, R_{o} l N^{\circ} 146$.

21 De Tocqueville, Alexis (1984) La democracia en América. Madrid: Ed. Sarpe, p. 112.

22 Mayor detalle puede encontrarse en Fernández GonZález, Miguel Ángel (2005) "La apelación en el nuevo proceso penal frente al Derecho Constitucional al debido proceso", Revista de Derecho Público, vol. LXVII, pp. 145-169. 
aquí interesa, el sistema de recursos contenido en dicho Código, sobre la base de lo preceptuado en su artículo 364, en virtud del cual son inapelables las resoluciones dictadas por un tribunal de juicio oral en lo penal. Por ello, la manera de atacar aquellas decisiones, de acuerdo a su artículo 362, es a través del recurso de reposición que se deduce, fundadamente y dentro de tercero día, ante el mismo tribunal que las pronunció.

Por su parte y tratándose de las resoluciones adoptadas por el juez de garantía, solo son apelables, conforme al artículo 370, las que ponen término al procedimiento, hacen imposible su prosecución o lo suspenden por más de treinta días y, también, cada vez que la ley señale, expresamente, la procedencia de aquel recurso.

A su turno, el artículo 372 inciso $1^{\circ}$ expresa que el recurso de nulidad se concede para invalidar el juicio oral y la sentencia definitiva, o solamente esta, por las causales expresamente señaladas en la ley, las cuales se encuentran contenidas en los artículos 373 y 374 del Código, correspondiendo el conocimiento de unas -las del primer artículo mencionado- a la Corte Suprema y las restantes a la Corte de Apelaciones respectiva.

De lo expuesto, surge, inmediatamente, que el Nuevo Código amino$\mathrm{ra}$, disminuye restringe o, derechamente, prohíbe la revisión completa de la causa, en los hechos y en el Derecho, por un tribunal superior, privilegiando o comprimiendo la competencia de Alzada al examen del Derecho y su aplicación.

Los anales fidedignos del Código Procesal Penal dan cuenta que el tema en examen fue controvertido, pero que se aceptó, en definitiva, el modelo antes resumido, por cuanto, entre otras razones, “(...) La oralidad del procedimiento requiere que el tribunal que conoce el juicio tenga el máximo poder de decisión. Si en vez de darle el poder de decisión final al tribunal que asiste al juicio oral se le otorga a otro tribunal, que conocerá de la causa por la vía de la lectura del expediente, se estaría poniendo el centro del debate en la lectura del expediente y no en el juicio oral. No solo se pondría el énfasis en la lectura del expediente sino que se terminaría privilegiando la opinión del tribunal menos informado por sobre la opinión del tribunal más informado" 23 .

\section{Examen constitucional}

Debe reconocerse que el régimen de recursos expuesto, no obstante las argumentaciones vertidas, provoca dudas de constitucionalidad, ya que se trata de una normativa que limita severamente la procedencia del recurso de apelación, sobre todo, si es que se llegara a considerar que todo lo actuado -en los hechos y en el De- 
recho-por un tribunal debe ser susceptible de revisión por otro como regla de respeto a esa especie de proceso.

"El problema al resolver, entonces era de orden constitucional. La supresión del recurso de apelación abría una discusión en torno a la mejor manera de defender los principios constitucionales del debido proceso y de garantizar el derecho de defensa (...).

A nuestro juicio, la decisión legislativa de suprimir en Chile el recurso de apelación en contra de las sentencias definitivas dictadas en juicio oral está lejos de sacrificar ninguna garantía fundamental. Habiéndose concebido en primera instancia un tribunal colegiado integrado por tres miembros, cuyas decisiones son impugnables a través del recurso de nulidad, y habiéndose estructurado este último como un recurso de nulidad, y habiéndose estructurado este último como un recurso desformalizado, que permite controlar, según veremos, el respeto a los derechos y garantías comprometidos en el procedimiento penal y la conformidad de la sentencia con las reglas de la sana crítica, la posibilidad de apelación habría resultado del todo superflua. Lo que resulta realmente trascendente desde el punto de vista del derecho al recurso no es la doble instancia, sino la doble conformidad (...)" 24 .

Lo anterior adquiere todavía mayor relevancia cuando la reducida procedencia del recurso de apelación puede conducir, como es obvio aventurar, a que sea reemplazado por el de nulidad previsto en los artículos $372^{\circ}$ y siguientes del Código Procesal Penal, con lo cual se puede provocar que se atiborre a la Corte Suprema -como ha ocurrido, en el Sistema Antiguo, con las Cortes de Apelacionesconforme a la causal prevista en el artículo $373^{\circ}$ letra a) del Código; y, tal vez como reacción a lo anterior, el recurso de nulidad va a ir perdiendo valor, haciendo que los procesos penales terminen siendo de única instancia ${ }^{25}$.

\section{Jurisprudencia nacional}

Evaluando el sistema contenido en el Código, traigo a la memoria que el Tribunal Constitucional, tratándose de un recurso de derecho estricto y más excepcional que el de apelación o el de nulidad en el Nuevo Código Procesal Penal, como es el de casación, sostuvo:

"La Constitución en el artículo 19, $\mathrm{N}^{\circ} 3$, asegura a todas las personas la igual protección de la ley en el ejercicio de sus derechos. Esto significa que los afectados que estimen que los tribunales de la instancia no ban aplicado correctamente la ley que regula su conflicto, tienen derecho a que esos errores sean corregidos por el máximo tribunal de la República, siendo únicamente ellos los que pueden calificar el agravio y perjuicio que le causa el vicio que afecta a la sentencia dictada con error de derecho.

24 Horvitz Lennon, María Inés y López Masle, Julián (2004) Derecho Procesal Chileno. Tomo II. Santiago: Ed. Jurídica de Chile, pp. 354-360. En el mismo sentido, aunque solo constatando los antecedentes históricos, Núñez VÁsquez, J. Cristóbal (2003) Tratado del proceso penal y del juicio oral. Tomo II. Santiago, Ed. Jurídica de Chile, pp. 289-290. 
El citado artículo señala que toda sentencia de un órgano que ejerza jurisdicción debe fundarse en un proceso previo legalmente tramitado, y agrega que corresponde al legislador establecer las garantías de un racional y justo procedimiento. La procedencia del recurso de casación en el fondo es uno de los instrumentos más importantes para dar eficacia a este derecho constitucional (...).

El establecimiento de recursos es una de las principales garantias que las partes tienen en el desarrollo del proceso (...)" 26 .

Sin embargo, recuerdo que se intentó someter el asunto de si la carencia de apelación vulneraba la Carta Fundamental, habiendo señalado el Tribunal, en el control de admisibilidad:

"Que, en efecto, consta del certificado estampado con fecha 10 de abril del año en curso por el Secretario de este Tribunal Constitucional, que la sentencia dictada en los referidos autos criminales -RIT 273-2006-, se encuentra ejecutoriada a contar del día 9 de abril de 2007.

En consecuencia, en este caso resulta evidente que no existe una gestión pendiente ante un tribunal ordinario o especial en la cual pudiera recibir aplicación el inciso segundo del artículo 387 (relativo a la improcedencia de recursos en contra de la resolución que falla un recurso de nulidad) del Código Procesal Penal, precepto que, como antes se ha indicado, es objeto del presente requerimiento;

Que, por otra parte, tampoco se cumple la exigencia constitucional según la cual la aplicación del precepto legal que se impugna pueda resultar decisiva en la resolución del asunto de que se trata. En este caso, la norma legal invocada no tiene incidencia en la decisión sustantiva de la gestión que ha motivado la interposición de la acción, atendida la naturaleza de la misma, esto es, que se trata de un juicio criminal que versa sobre los delitos aludidos en el considerando primero" 27.

\section{Jurisprudencia internacional}

El 2 de julio de 2004, la Corte Interamericana de Derechos Humanos se pronunció en Herrera Ulloa con Costa Rica y lo hizo en términos que ponen en entredicho el régimen de recursos previsto en el Código:

"Los Estados tienen la responsabilidad de consagrar normativamente y de asegurar la debida aplicación de los recursos efectivos y las garantías del debido proceso legal ante las autoridades competentes, que amparen a todas las personas bajo su jurisdicción contra actos que violen sus derechos fundamentales o que conlleven a la determinación de los derechos y obligaciones de estas (...).

En relación con el proceso penal, es menester señalar que la Corte, al referirse a las garantías judiciales, también conocidas como garantías procesales, ha mismo sentido, considerandos $16^{\circ}$ y $17^{\circ}$ de la sentencia pronunciada el 30 de mayo de 2007 , Rol N 664 .
} 
establecido que para que en un proceso existan verdaderamente dichas garantías, conforme a las disposiciones del artículo $8^{\circ}$ de la Convención, es preciso que se observen todos los requisitos que 'sirvan para proteger, asegurar o hacer valer la titularidad o el ejercicio de un derecho', es decir, las 'condiciones que deben cumplirse para asegurar la adecuada defensa de aquellos cuyos derechos u obligaciones están bajo consideración judicial (...)'.

De conformidad con la legislación costarricense, contra una sentencia condenatoria emitida en el proceso penal solamente se puede interponer el recurso de casación (...).

La Corte ha indicado que el derecho de recurrir del fallo, consagrado por la Convención, no se satisface con la mera existencia de un órgano de grado superior al que juzgó y condenó al inculpado, ante el que este tenga o pueda tener acceso. Para que haya una verdadera revisión de la sentencia, en el sentido requerido por la Convención, es preciso que el tribunal superior reúna las características jurisdiccionales que lo legitiman para conocer del caso concreto. Conviene subrayar que el proceso penal es uno solo a través de sus diversas etapas, incluyendo la tramitación de los recursos ordinarios que se interpongan contra la sentencia (...).

El juez o tribunal superior encargado de resolver el recurso interpuesto contra la sentencia penal tiene el deber especial de protección de las garantías judiciales y el debido proceso a todas las partes que intervienen en el proceso penal de conformidad con los principios que lo rigen (...).

Independientemente de la denominación que se le de al recurso existente para recurrir un fallo, lo importante es que dicho recurso garantice una examen integral de la decisión recurrida" 28 .

Por cuanto viene siendo expuesto, no puede menos que concluirse que la regla de la doble instancia forma parte del derecho al debido proceso, con lo cual la competencia del Tribunal de Alzada tiene que extenderse y comprender tanto la revisión de los hechos y del Derecho cuanto la evaluación acerca de la apreciación que de la prueba haya realizado el Tribunal Inferior.

\section{Nulidad POR INFRACCión dE LA CONSTITUCión O DE LOS Tratados}

A partir de las consideraciones expuestas, examino a continuación, brevemente, algunas cuestiones directamente vinculadas con la causal de nulidad, del juicio oral y de la sentencia definitiva o solamente de esta, contemplada en el artículo 373 letra a) del Código Procesal Penal. 


\section{Antecedentes}

Útil es recordar, siguiendo el resumen que realiza el profesor PFEFFER, que el recurso de nulidad contemplado en la causal aludida tuvo su origen en el Senado, durante el segundo trámite del proyecto de ley que contenía el Código Procesal Penal. En dicha Corporación se alteró, sustancialmente, la propuesta formulada por la Cámara de Diputados, reemplazando y reformulando los recursos de casación y extraordinario, para incorporar el de nulidad, aliviando la carga de la Corte Suprema para que pudiera poner énfasis en el gobierno judicial.

"Es, por tanto, un recurso que apunta a dos objetivos perfectamente diferenciados: la cautela del racional y justo procedimiento (mediante el pronunciamiento de un tribunal superior sobre si ha habido o no respeto por las garantías básicas en el juicio oral y en la sentencia recaída en él, de forma que, si no hubiese sido así, los anule) y el respeto de la correcta aplicación de la ley (elemento que informa el recurso de casación clásico, orientado a que el legislador tenga certeza de que los jueces van a atenerse a su mandato), pero ampliado en general a la correcta aplicación del derecho, para incorporar también otras fuentes formales integrantes del ordenamiento jurídico" 29 .

En el contexto descrito, examino algunos temas específicos vinculados con el recurso de nulidad, consistentes en la oportunidad en que debe haberse producido la infracción recurrida; si el Ministerio Público puede deducir ese recurso por la causal contemplada en el artículo 373 letra a) del Código; cuál es la entidad del vicio objeto del arbitrio de nulidad; y, en fin, el objeto sobre el cual debe recaer el vicio reclamado.

\section{Oportunidad de la infracción}

En primer lugar, según dispone el artículo 373 letra a) del Código Procesal Penal, es menester que la infracción se haya producido en cualquier etapa del procedimiento o en el pronunciamiento de la sentencia.

Sabemos que, en este punto, el artículo referido fue modificado, en $2005^{30}$, pues, en su texto original disponía que la infracción tenía que haberse producido en la tramitación del juicio o en el pronunciamiento de la sentencia, con el objeto de poner fin a la jurisprudencia "(...) bastante uniforme [que] había insistido en que los vicios o defectos en los que se haya podido incurrir con anterioridad al juicio oral, en particular, aquellas infracciones cometidas en la etapa de investigación, no podían servir para

29

Pfeffer (2001) 369. Más detalle puede encontrarse en VV.AA. (2003) Reforma procesal penal. Génesis, bistoria sistematizada y concordancias. Santiago: Facultad de Derecho de la Universidad de Chile, Ed. Jurídica de Chile, pp. 79-105.

30

Ley $\mathrm{N}^{\circ} 20.074$, publicada en el Diario Oficial el 14 de noviembre de 2005. 
fundamentar un recurso de nulidad" 31 , concretamente, los cometidos durante la etapa de investigación:

"Que basta para rechazar el recurso de nulidad planteado la clara disposición que se contempla en el artículo 161 del Código Procesal Penal. En efecto, no podrá reclamarse la nulidad de actuaciones verificadas durante la etapa de investigación, después de la audiencia de preparación del juicio oral (...)"32, aunque también se ha pronunciado jurisprudencia en sentido contrario, efectuando una interpretación desde y hacia la Constitución ${ }^{33}$.

Sin embargo, aun después de la reforma introducida por la Ley $\mathrm{N}^{\circ} 20.074$, la Corte ha negado lugar a la nulidad, v. gr., cuando se invoca un vicio que se concretará en el cumplimiento alternativo de la pena. Se trataba de un condenado que sostenía que se vulneraba su derecho a la libertad personal, asegurado en el artículo $19 \mathrm{~N}^{\circ} 7^{\circ}$ de la Constitución, cuando se le hacían exigencias pecuniarias para que procediera la libertad vigilada, en circunstancias que él estimaba derogado el precepto legal que imponía aquellas exigencias:

“(...) De lo anterior se sigue que la infracción denunciada para fundar el recurso ha de haberse cometido en la sentencia definitiva, lo que no ocurre en la especie, puesto que el reproche se dirige a la forma en que se ha concedido al imputado un beneficio de cumplimiento alternativo de la pena, resolución que aunque se adopte al momento de dictar el fallo y se incluya materialmente en este, no reviste el carácter de sentencia definitiva, en los términos del artículo 158 del Código de Procedimiento Civil (...)"34.

Con todo y a pesar de la claridad de la reforma, ha subsistido la duda acerca de si es posible extender el recurso de nulidad a vicios acaecidos durante la fase de investigación. De hecho, la Corte Suprema lo ha negado, v. gr., en las sentencias pronunciadas el 10 y 15 de mayo de $2006^{35}$.

En este sentido, el muy buen libro de Rieutord explica que “(...) la opinión mayoritaria se inclina por restringir el alcance de los efectos del recurso de nulidad solo a vicios producidos en el juicio y la sentencia y, por consiguiente, entienden que a través del recurso de nulidad sería imposible atacar vicios producidos en la etapa de investigación (...)"36.

31 Cortez Matcovich, Gonzalo (2006), El recurso de nulidad, Santiago, Ed. LexisNexis, 2006, p. 146.

32 Considerando $8^{\circ}$ de la sentencia pronunciada el 30 de junio de 2003, Rol $N^{\circ} 1.830-03$, Revista Procesal Penal Tomo III, Santiago, Ed. LexisNexis, 2005, p. 213.

33 Considerando $5^{\circ}$ de la sentencia pronunciada por la Corte Suprema el 29 de octubre de 2002, Rol N 3.319-02, Revista Procesal Penal, citada en supra nota 33, tomo I, 2005, p. 502.

34 Considerando $3^{\circ}$ de la sentencia pronunciada el 3 de abril de 2003 , Rol N ${ }^{\circ} 768-03$, Revista Procesal Penal, citada en supra nota 33, tomo II, 2005, p. 560.

$35 \quad$ Rol N ${ }^{\circ} 879-06$ y Rol N ${ }^{\circ} 1.703-06$, respectivamente.

36 Rieutord Alvarado, Andrés (2007) El recurso de nulidad en el nuevo proceso penal. Santiago: Ed. Jurídica de Chile, pp. 20-21. 


\subsection{Argumentos en contra}

Ello, en primer lugar, sobre la base del tenor literal del artículo 372 del Código Procesal Penal, en virtud del cual "el recurso de nulidad se concede para invalidar el juicio oral y la sentencia o solamente esta", con lo cual no alcanzaría a otros actos anteriores a aquel juicio.

En segundo lugar, por lo dispuesto en los artículos 161 y 165 del Código que obligan a impetrar la nulidad dentro de los cinco días siguientes a aquel en que se haya tomado conocimiento del vicio y que impiden retrotraer, con la declaración de nulidad, el procedimiento a etapas anteriores, añadiendo el último precepto mencionado que "si durante la audiencia de preparación del juicio oral se declarare la nulidad de actuaciones judiciales realizadas durante la etapa de investigación, el tribunal no podrá ordenar la reapertura de esta. Asimismo, las nulidades declaradas durante el desarrollo de la audiencia del juicio oral no retrotraerán el procedimiento a la etapa de investigación o a la audiencia de preparación del juicio oral (...)".

Empero y mencionando de inmediato un contraargumento, la norma legal recién copiada sigue señalando que "la solicitud de nulidad constituirá preparación suficiente del recurso de nulidad para el caso que el tribunal no resolviere la cuestión de conformidad a los solicitado".

\subsection{Argumentos a favor}

Por lo expuesto, coincido con Rieutord, cuando señala que es posible sustentar que el recurso de nulidad alcanza a etapas anteriores del juicio oral. Para este efecto acude al artículo 165, en la frase ya transcrita, y en aquella otra que, si bien prohíbe retrotraer el procedimiento a la etapa de investigación o a la audiencia de preparación del juicio oral, como se ha transcrito, admite que ello se haga "en los casos en que correspondiere de acuerdo con las normas del recurso de nulidad".

En la misma línea de pensamiento, se mencionan los artículos 277 inciso penúltimo, la nueva redacción del artículo 373 letra a) y el artículo 386.

Así ha obrado la Corte Suprema recientemente, v. gr., en la sentencia pronunciada el 11 de junio de 2007:

"Que con la reforma hecha por la Ley $\mathrm{N}^{\circ} 20.074$, de 14 de noviembre de 2005, a la letra a) del artículo 373 del Código Procesal Penal, es ahora procesalmente posible declarar la nulidad del juicio oral y de la sentencia cuando, en cualquier etapa del procedimiento o en el pronunciamiento de la sentencia se hubieren infringido sustancialmente derecho o garantías asegurados por la Constitución o por los tratados internacionales ratificados por Chile que se encuentren vigentes, y en correspondencia con lo que dispone el artículo $7^{\circ}$ del mismo cuerpo legal las facultades, derechos y 
garantías que la Constitución Política de la República, el Código Procesal Penal y otras leyes reconocen al imputado puede hacerlas valer desde las primeras actuaciones del procedimiento, entendiendo por tales cualquiera diligencia o gestión, sea de investigación, de carácter cautelar o de otra especie, que se realizare por o ante un tribunal con competencia criminal, el Ministerio Público o la policía, en la que se atribuye a una persona responsabilidad en un hecho punible. El perjuicio, elemento esencial cuando se trata de nulidades procesales, en este caso la ley lo presume de derecho pues se ha impedido el pleno ejercicio de las garantías y de los derechos reconocidos en la Constitución, o en las demás leyes de la República, como lo sanciona el artículo 160 del Código de Enjuiciamiento Penal"37.

Finalmente, si se admite que es posible acoger el recurso de nulidad por vicios cometidos con anterioridad al juicio oral, en la etapa de investigación, será menester resolver si el juicio se retrotrae a la audiencia del juicio oral o si la sentencia de la Corte Suprema que lo acoge simplemente ordena la exclusión de la prueba viciada, lo cual debe ser determinado en cada caso por la sentencia que declara la nulidad, sin que esté prohibido volver, incluso, al estado anterior a la audiencia de preparación del juicio oral.

\section{Legitimación activa}

En esta segunda materia, fuertemente debatida, la discusión se ha situado en torno a si el Ministerio Público, como interviniente en el proceso penal, puede demandar la nulidad contemplada en el artículo 373 letra a) del Código del ramo.

Si bien la doctrina y, en algunos casos, la jurisprudencia ha sostenido que “(...) resulta del todo contradictorio que el Ministerio Público, representante exclusivo y excluyente del Estado en el ámbito de la persecución penal, pretenda, invocando el señalado fundamento, reclamar, a través del recurso de nulidad, de la infracción de garantías constitucionales en su perjuicio, suponiendo un estatus de igualdad con la persona objeto de la persecución penal" ${ }^{38}$, en otras oportunidades se ha reconocido que el derecho del Ministerio Público puede impetrar ese arbitrio:

“(...) siendo el Ministerio Público un interviniente tiene derecho a la 'igual protección de la ley en el ejercicio de sus derechos' lo que, a su juicio, en su manifestación procesal-procedimental se traduce tanto en el derecho a igual tratamiento como a que se le asegure un debido proceso (...)"39.

\footnotetext{
37 Considerando $5^{\circ}$ de la sentencia Rol $N^{\circ}$ 1.836-(07. En el mismo sentido, la sentencia pronunciada el 6 de junio de 2007, Rol N ${ }^{\circ} 678-07$.

RIEUTORD (2007) 42.

Considerando $3^{\circ}$ de la sentencia pronunciada el 31 de marzo de 2003, Revista Procesal Penal, citada en supra nota 33, p. 414. En contra, véase el voto de minoría contenido en la misma sentencia, pp. 418-419.
} 
Así ha ocurrido cuando el Tribunal Oral negó lugar a la declaración de un testigo de cargo porque estaba mal individualizado en el acta de apertura del juicio oral ${ }^{40}$.

Con todo, el fundamento constitucional, para sostener que el Ministerio Público puede recurrir de nulidad, por la causal del artículo 373 letra a) del Código, se encuentra en el carácter objetivo de que también gozan los derechos fundamentales, ya que estos derechos “(...) son la expresión más inmediata de la dignidad humana, y desde esta perspectiva es indiscutible que presentan sustancialmente una vertiente subjetiva que se traduce en la posibilidad de un agere licere dentro de un determinado ámbito. Sin embargo y como creemos que se desprende con facilidad de todo lo inmediatamente antes expuesto, los derechos fundamentales poseen además otras significación, esta vez, objetiva (...)"41.

Por ello, cuando el Ministerio Público invoca la vulneración de los derechos y garantías asegurados en la Constitución o en tratados internacionales, no lo hace en condición o calidad de titular de esos atributos, sino en defensa de ellos, en su faz objetiva, como institución estructurante del ordenamiento jurídico y, por ende, del Estado Democrático y Constitucional de Derecho, ya que son "(...) la conditio sine qua non [de esa especie de Estado], puesto que no pueden dejar de ser pensados sin que peligre la forma de Estado o se transforme radicalmente. Por lo mismo, hoy se admite de modo generalizado que los derechos cumplen 'funciones estructurales' de suma importancia para los principios conformadores de la Constitución" 42 .

\section{Naturaleza de la infracción}

En tercer lugar, la infracción de los derechos o garantías asegurados por la Constitución o por los tratados internacionales, admite el recurso de nulidad solo cuando esa infracción sea sustancial, es decir, siguiendo a CoRTEZ, “(...) cuando el tribunal haya aplicado el derecho a un caso concreto de modo incompatible con los derechos o garantías asegurados por la Constitución o por los tratados internacionales ratificados por Chile que se encuentren vigentes o bien cuando se haya dejado de aplicar un precepto que debió haber sido aplicado. Que la infracción sea sustancial, señala López, significado que debe ser de tal entidad que comprometa aspectos esenciales de la garantía"43.

Considerando $13^{\circ}$ de la sentencia pronunciada el 31 de marzo de 2003, Revista Procesal Penal, citada en supra nota 33, p. 417. Cfr. Sentencia pronunciada el 9 de abril de 2003, reproducida en la misma Revista, pp. 567-571, donde se niega el recurso de nulidad deducido por el Ministerio Público porque no solicitó, en tiempo, la recepción anticipada de la declaración de un perito. Revista Española de Derecho Constitucional, Año 13, número 39, septiembre-diciembre, p. 207. FERNÁNDEZ (1993) 207.

Cortez Matcovich (2006) 146. 
Complementando lo anterior, RiEutord expone que, si bien no se ha impuesto un criterio definitivo, asimilar el requisito de sustancialidad a que el vicio influya sustancialmente en lo dispositivo del fallo, “(...) genera, a nuestro juicio, algunos inconvenientes, pues una infracción sustancial de garantías en el juicio o necesariamente podrá verse reflejada en la sentencia respectiva (...)" 44 .

A su turno, la Corte Suprema ha explicado que se trata de una infracción que "(...) sea trascendente, de mucha importancia o gravedad, de tal modo que el defecto sea, en definitiva, insalvablemente ineficaz frente al derecho constitucional (...)" 45 .

Por ello, en este caso, desestimó el recurso que se fundaba en irregularidades cometidas en el reconocimiento del imputado y en la cadena de custodia del arma con que se había perpetrado el delito, consistentes en que fue reconocido en el radiopatrulla y en que la pistola fue indebidamente manipulada por Carabineros, ya que “(...) aun aceptando, lo que no está demostrado por quien recurre, que no se observó prolijamente los detalles procesales de la incautación del arma, su cadena de custodia y con el reconocimiento que hizo la víctima respecto del detenido, el que por lo demás corresponde claramente al de un delito flagrante, lo cierto es que esas probables deficiencias no tienen el carácter de sustanciales (...)" 46 .

Por otra parte, no se reputa sustancial la infracción cuando ella configura una causal de nulidad diversa, ya que "(...) de existir, no afecta sustancialmente el principio del debido proceso de ley, toda vez que la aplicación errónea de la ley penal es causal prevista en la letra b) del artículo $373(\ldots)^{\prime 4} 4$.

En consecuencia, que la infracción sea sustancial implica que ella vulnere los derechos y garantías de manera que, sobre esa base, se prive o lesione su ejercicio, sin que se requiera de una cuestión en extremo grave o insuperable, aumentando indebidamente el estándar exigido por la ley.

\section{Objeto de la infracción}

Finalmente, señalo que, para la procedencia de la nulidad, es menester que, en cualquier etapa del procedimiento o en el pronunciamiento de la sentencia, se hayan infringido los derechos o garantías asegurados por la

45 Considerando $9^{\circ}$ de la sentencia pronunciada por la Corte Suprema el 29 de octubre de 2002, Rol N³.319-02, Revista Procesal Penal, citada en supra nota 33, tomo I, 2002, p. 503.

46 Considerando $9^{\circ}$ de la sentencia pronunciada por la Corte Suprema el 29 de octubre de 2002, Rol N 3.319-02, Revista Procesal Penal, citada en supra nota 33, tomo I, 2002, pp. 503-504.

47 Sentencia pronunciada por la Corte Suprema el 5 de sepriembre de 2001, Rol N ${ }^{\circ} 3.154-01$, Revista Procesal Penal, citada en supra nota 33, tomo I, 2005, p. 73.
} 
Constitución o por los tratados internacionales ratificados por Chile que se encuentren vigentes.

Al respecto, NúÑEZ señala que "al mencionar la ley los 'derechos', hace alusión a las prerrogativas que la Constitución, las leyes y los tratados internacionales aseguran, tales como la libertad personal, la igualdad ante la ley, la presunción de inocencia, el debido proceso, la defensa en juicio, la revisión del fallo condenatorio por un tribunal superior y otros; y al apuntar a las garantías, se refiere a las acciones y recursos que resguardan los primeros, todos los cuales deben estar expresamente establecidos en la Carta Fundamental o en los referidos tratados internacionales ratificados por Chile y actualmente vigentes, tales como el Código de Derecho Internacional Privado o el Pacto de San José de Costa Rica"48.

Ciertamente, no es posible condensar todas las posibilidades de infracción de derechos y garantías constitucionales o de tratados internacionales ${ }^{49}$. Empero, me parece interesante mencionar que se ha recurrido de nulidad por infracción:

- De los derechos asegurados en el artículo $19 \mathrm{~N}^{\circ} 3^{\circ}$ incisos $7^{\circ}$ y $8^{\circ}$, o sea, por normas que configuran las bases constitucionales del Derecho Penal, tales como los principios de tipicidad y legalidad ${ }^{50}$;

- Del derecho asegurado en el artículo $19 \mathrm{~N}^{\circ} 7^{\circ}$ de la Constitución, específicamente, cuando se considera que la norma en virtud de la cual se hacen exigencias pecuniarias para que proceda la libertad vigilada se encuentra derogada por la Carta Fundamental ${ }^{51}$;

- Del derecho asegurado en el artículo $19 \mathrm{~N}^{\circ} 4^{\circ}$ y $\mathrm{N}^{\circ} 5^{\circ}$ porque el agente encubierto habría vulnerado el derecho a la vida privada y a la inviolabilidad del hogar, al "(...) haber ingresado a la vivienda del imputado y haberse enterado de su vida familiar para los fines de la investigación que realizaba" 52 , lo cual fue desestimado por la Corte.

- Del derecho asegurado en el artículo $19 \mathrm{~N}^{\circ} 12^{\circ}$, porque se estimó vulnerada la libertad de expresión, al efectuarse por el tribunal una errada interpretación de las normas sobre exceptio veritatis contenida en la Ley $\mathrm{N}^{\circ} 19.733^{53}$.

49 El examen más prolijo y completo en esta materia se encuentra en CORTEz MaTCOVICH (2006) 149-170.

Sentencia pronunciada el 31 de enero de 2002, Rol No 4.406-2001, Revista Procesal Penal, citada en supra nota 33, tomo I, pp. 46-49.

Considerando $3^{\circ}$ de la sentencia pronunciada el 3 de abril de 2003, Rol $N^{\circ} 768-03$, Revista Procesal Penal, citada en supra nota 33, tomo II, p. 560.

52 Considerando $7^{\circ}$ de la sentencia pronunciada el 5 de junio de 2003 , Rol N ${ }^{\circ} 1.496-03$, Revista Procesal Penal, citada en supra nota 33, tomo III, p. 207. citada en supra nota 33, tomo VII, pp. 61-74.
} 
Es menester recordar, en esta materia, que la Corte Suprema ha exigido precisión en los preceptos infringidos:

“(...) aduciéndose en relación a la letra a) de dicha disposición, que se han violado derechos fundamentales protegidos por la Carta Fundamental, haciendo alusión en términos genéricos al debido proceso, sin invocar en consecuencia con la correspondiente precisión qué otras normas constitucionales o contenidas en un tratado internacional se han vulnerado con la dictación de la sentencia impugnada (...)"54.

Más aún, ha declarado inadmisible el recurso que "(...) no contiene un desarrollo respecto de la relación que existiría entre las infracciones denunciadas y la garantía constitucional que se dice vulnerada (...)"55 o cuando se interpone el recurso por varias causales "(...) sin especificar si dichas causales se interponen conjunta o subsidiariamente (...)"56.

Para terminar y tratándose del debido proceso, es menester advertir que su infracción no se reduce a la vulneración de lo preceptuado en el artículo $19 \mathrm{~N}^{\circ} 3^{\circ}$, especialmente, en cuanto a los derechos a defensa y al juez natural y a los principios básicos del Derecho Penal, como son los de legalidad, tipicidad e irretroactividad; ni siquiera puede reducírselo a los que contemplan los tratados internacionales vigentes en nuestro país, como por ejemplo, las graantías judiciales previstas en el artículo $8^{\circ}$ de la Convención Americana.

Incluyendo todo ello, el debido proceso implica que los órganos estatales involucrados en el proecso penal, en sus fases investigativa y jurisidiccional no solo tienen que ser respetuosos de la legalidad procesal, sino que de los requisitos de racionalidad y justicia, cuyo acatamiento es exigido desde la misma Constitución. De esta manera, el respeto del derecho al debido proceso no consiste solo en verificar que se acate aquella legalidad procesal, sino que, superlativamente y con independencia de ella, que haya respeto por los elementos sustantivos requeridos en la Carta Fundamental, complementada por los tratados internacionales, de acuerdo con lo exigido en su artículo $5^{\circ}$ inciso $2^{\circ}$.

\section{Conclusiones}

Al finalizar, reitero $\mathrm{mi}$ agradecimiento a los organizadores de este encuentro académico conjunto, especialmente, al profesor Kamel Cazor y

\footnotetext{
54 Sentencia pronunciada por la Corte Suprema el 30 de enero de 2002, Rol N ${ }^{\circ} 5.018-01, R e-$ vista Procesal Penal, citada en supra nota 33, tomo I, 2002, p. 51.

55 Considerando $3^{\circ}$ de la sentencia pronunciada por la Corte Suprema el 9 de enero de 2003, Rol N 4.714-02, Revista Procesal Penal, citada en supra nota 33, tomo II, 2005, p. 61.

56 Considerando $2^{\circ}$ de la sentencia pronunciada el 6 de diciembre de 2004 , Rol $N^{\circ}$ 5.065-04, Revista Procesal Penal, citada en supra nota 33, tomo VII, p. 727.
} 
a quienes han colaborado a su realización, reafirmando que la causal de nulidad, contemplada en el artículo 373 letra a) del Código Procesal Penal, es denotativa del fenómeno de la constitucionalización del Derecho que, es de esperar, sea un proceso, en desarrollo y avance, de mayor respeto y promoción de los derechos de las personas.

Consistente con lo anterior, me parece indudable que el vicio susceptible de ser reclamado puede haberse producido incluso en la etapa de investigación; que el Ministerio Público puede invocar la vulneración de derechos y garantías para acudir a ese arbitrtio procesal, en cuanto principios estructurantes del Estado Democrático y Constitucional de Derecho; que la exigencia en orden a que el vicio sea sustancial no puede ser exagerada, hasta dejar al recurso desprovisto de vigencia, pues lo que está en juego son derechos fundamentales, donde la entidad del agravio no resulta relevante; y que lo vulnerado pueden ser tanto los derechos $-\mathrm{y}$ todos ellos, no solo el debido proceso, en su vertiente formal y también desde el ángulo material, sobre la base de la racionalidad y justicia que exige a los órganos públicos-cuanto las garantías destinadas a protegerlos.

\section{Bibliografía}

- Bulnes Aldunate, Luz (1998) "La fuerza normativa de la Constitución”. Revista Chilena de Derecho, Número Especial.

- Cea Egaña, José Luis (1990) "El Parlamento en el futuro del Derecho y de la democracia”. Revista Chilena de Derecho, vol XVII N ${ }^{\circ} 1$.

(1999) El sistema constitucional de Chile. Síntesis crítica. Valdivia: Facultad de Ciencias Jurídicas y Sociales de la Universidad Austral de Chile.

(2002) Derecho Constitucional Chileno. Tomo I. Santiago: Ediciones Universidad Católica de Chile.

(2003) "Aproximación a la teoría constitucional contemporánea”. Estudios Constitucionales, Año $1 \mathrm{~N}^{\circ} 1$.

- Cortez Matcovich, Gonzalo (2006), El recurso de nulidad, Santiago, Ed. LexisNexis, 2006.

- De Tocqueville, Alexis (1984) La democracia en América. Madrid: Ed. Sarpe.

- Domínguez Águila, Ramón (1999) "Prólogo". Castellón VeneGas, Hugo A. y Rebolledo Contreras, Laura E. Aspectos sobre la constitucionalización del Derecho Civil. Santiago: Ed. ConoSur.

- Fernández González, Miguel Ángel (1999) "Recurso de protección y jurisdicción doméstica”, Revista Chilena de Derecho, Vol. XXVI $\mathrm{N}^{\circ} 3$.

de Derecho Público Vol. LXIII, tomo I. 
(2002) "Fundamentos constitucionales del derecho de los contratos: Intangibilidad, autonomía de la voluntad y buena fe". En Hernán Corral Talciani (editor). Cuadernos de Extensión Jurídica $\mathrm{N}^{\circ} 6$, Universidad de los Andes.

(2003) "Renunciabilidad de los derechos fundamentales de contenido económico". En Actas del VIII Congreso Iberoamericano de Derecho Constitucional, Sevilla: 3 al 5 de diciembre [versión en CD].

- (2004) "Constitucionalización del Derecho Civil. Eficacia horizontal y renunciabilidad de los derechos fundamentales". Temas de Derecho, Universidad Gabriela Mistral, Año XIX N ${ }^{\circ} 1$ y 2.

- (2005) "Bases de los Tribunales Constitucionales en el constitucionalismo humanista". Humberto Nogueira Alcalá (coordinador) Jurisdicción constitucional en Chile y América Latina: presente y prospectiva, Santiago: LexisNexis.

- _ (2005) "Constitución y casación: ¿de la falta de aplicación al monopolio constitucional?". Estudios Constitucionales, Año $3 \mathrm{~N}^{\circ} 1$. (2005) "La apelación en el nuevo proceso penal frente al Derecho Constitucional al debido proceso", Revista de Derecho Público, vol. LXVII.

- Fernández Segado, Francisco (1993) "La teoría jurídica de los derechos fundamentales". Revista Española de Derecho Constitucional, Año 13 , número 39 , septiembre-diciembre.

- Horvitz Lennon, María Inés y López Masle, Julián (2004) Derecho Procesal Chileno. Tomo II. Santiago: Ed. Jurídica de Chile.

- Lovera Parmo, Domingo (2005), "Notas sobre el control de constitucionalidad de las sentencias y el recurso de nulidad". Gaceta Jurídica $\mathrm{N}^{\circ} 305$.

- Montesquieu (1984) Del espíritu de las leyes. Madrid: Ed. Sarpe.

- NúÑez Vásquez, J. Cristóbal (2003) Tratado del proceso penal y del juicio oral. Tomo II. Santiago, Ed. Jurídica de Chile.

- Pfeffer Urquiaga, Emilio (2001) Código Procesal Penal anotado y concordado. Santiago, Ed. Jurídica de Chile.

- Ribas Maura, Andrés (1991) La cuestión de inconstitucionalidad. Madrid: Civitas.

- Rieutord Alvarado, Andrés (2007) El recurso de nulidad en el nuevo proceso penal. Santiago: Ed. Jurídica de Chile.

- Rioseco Enríquez, Emilio (1996) El Derecho Civil y la Constitución ante la jurisprudencia. Santiago: Editorial Jurídica de Chile.

- Roxin, Claus (2000) Derecho Procesal Penal. Buenos Aires: Ediciones del Puerto.

- Tavolari Oliveros, Raúl (2003) “Informe en Derecho: La garantía del debido proceso como causal de nulidad a invocar por el Ministerio Público". Boletín de Jurisprudencia del Ministerio Público $\mathrm{N}^{\circ} 15$. 
- Tomás y Valiente, Francisco (1996), A orillas del Estado, Madrid: Taurus.

- VV.AA. (2003) Reforma procesal penal. Génesis, historia sistematizada $y$ concordancias. Santiago: Facultad de Derecho de la Universidad de Chile - Ed. Jurídica de Chile. 